\title{
Surgical approaches for the management of idiopathic thoracic scoliosis and the indications for combined anterior-posterior technique
}

\author{
Michael J. Rauzzino, M.D., Christopher I. Shaffrey, M.D., James Wagner, M.D., Russ Nockels, \\ M.D., and Mark Abel, M.D.
}

Departments of Neurosurgery and Surgery, Henry Ford Hospitals, Detroit, Michigan; and Department of Orthopaedic Surgery, University of Virginia Medical Center, Charlottesville, Virginia

The indications for surgical intervention in patients with idiopathic scoliosis have been well defined. The goals of surgery are to achieve fusion and arrest progressive curvature while restoring normal coronal and sagittal balance. As first introduced by Harrington, posterior fusion, the gold standard of treatment, has a proven record of success. More recently, anterior techniques for performing fusion procedures via either a thoracotomy or a retroperitoneal approach have been popularized in attempts to achieve better correction of curvature, preserve motion segments, and avoid some of the complications of posterior fusion such as the development of the flat-back syndrome. Anterior instrumentation alone, although effective, can be kyphogenic and has been shown to be associated with complications such as pseudarthrosis and instrumentation failure. Performing a combined approach in patients with scoliosis and other deformities has become an increasingly popular procedure to achieve superior correction of deformity and to minimize later complications. Indications for a combined approach (usually consisting of anterior release, arthrodesis with or without use of instrumentation, and posterior segmental fusion) include: prevention of crankshaft phenomenon in juvenile or skeletally immature adolescents; correction of large curves $\left(75^{\circ}\right)$ or excessively rigid curves in skeletally mature or immature patients; correction of curves with large sagittal-plane deformities such as thoracic kyphosis $\left(>90^{\circ}\right)$ or thoracic lordosis $\left(>20^{\circ}\right)$; and correction of thoracolumbar curves that need to be fused to the sacrum. Surgery may be performed either in a staged proceedure or, more commonly, in a single sitting. The authors discuss techniques for combined surgery and complication avoidance.

\section{Key Words * idiopathic scoliosis * spinal deformity * combined anterior-posterior approach * complication avoidance}

The natural history of idiopathic scoliosis has been well studied, and relatively clear indications exist as to those patients who should be managed conservatively, either by brace therapy or serial observation, and those who require surgical intervention to prevent progressive scoliosis. In patients at high risk for developing a significant deformity early surgical intervention is frequently required. The goals of surgery 
in patients with scoliosis are correction of deformity, fusion with growth arrest to prevent curvature progression, and attainment of a functional spinal column with good sagittal and coronal balance. Three management strategies are used in the surgical treatment of idiopathic scoliosis: 1) isolated posterior approach, 2) isolated anterior approach, and 3) combined anterior-posterior approach. In this paper we will provide a brief overview of idiopathic scoliosis and examine the various surgical approaches, with special attention to those patients who are best surgically managed via a combined anterior-posterior approach.

\section{OVERVIEW OF IDIOPATHIC SCOLIOSIS}

Idiopathic scoliosis is a three-dimensional deformity generated by a structural lateral (coronal) curve of the spine for which, unlike neuromuscular or congenital scoliosis, no underlying cause can be established. It is therefore a diagnosis of exclusion. The etiology of idiopathic scoliosis is not clearly established. Theories based on genetics, growth aspects, and structural and biochemical changes in discs and muscles as well as central nervous system changes have been postulated.[54] The prevalence of idiopathic scoliosis in adolescent patients varies depending on the magnitude of the curve used for the diagnostic criterion. A curve of $10^{\circ}$, as measured by the Cobb method, has been accepted as the lower limit for the diagnosis of idiopathic scoliosis. Two to 3\% of the adolescent population (aged 10-16 years) exhibit a spinal curvature greater than or equal to $10^{\circ}$ and technically have scoliosis. The majority of patients with "scoliosis" will never require any form of treatment. As curve magnitude increases, prevalence decreases. A prevalence of 0.3 to $0.5 \%$ exists for curves in excess of $20^{\circ}$ whereas the prevalence of curves in excess of $40^{\circ}$ is $0.1 \%$. The male/female prevalence is equal for small curves $\left(<10^{\circ}\right)$, but curves greater than $20^{\circ}$ are 10 times more likely to present in women.[55,56]

A variety of curve patterns are commonly observed. In order of frequency they include: right thoracic, and left lumbar; right thoracolumbar; double thoracic; and left thoracic curves.[55,56] A classification for curvatures in idiopathic scoliosis has been proposed by King and associates[26] based on a review of frontal radiographs obtained in 405 cases of thoracic idiopathic scoliosis. The classification, which includes five curve patterns, is based on the number, flexibility, and deviation of the curves from the midline. Types 1 and 2 are described as double, right thoracic, and left lumbar curves in which the apical vertebrae of both curves are off the center sacral line. In type 1, the lumbar curves are shown to be more dominant and less flexible on side-bending radiographs than the thoracic curve. In type 2 curves, the thoracic curves are characterized as dominant, and the lumbar curves are more flexible. Types 3 and 4 are single major thoracic or thoracolumbar curves in association with a fractional (compensatory) lumbar curve. In type 3 curves the apex is observed around T-8 and end at L-3 or above. Type 4 curves are longer so that the L-4 vertebra tilts into the curve. The type 5 pattern is described as a double thoracic curve in which T-1 tilts into the upper thoracic curve. Lenke and associates[29] proposed a newer classification for thoracic curves based on the identification of six types of curve patterns and their relationship to a center sacral vertebral line as drawn on a standing 36-inch anteroposterior radiograph. Based on the relationship of the compensatory lumbar deformity, the curve is classified as types A, B, or C. A sagittal-plane modifier is used to measure the amount of kyphosis present on the lateral radiograph.

\section{INDICATIONS FOR TREATMENT}

\section{Adolescents and Adults}

When deciding treatment strategies, it is necessary to understand the natural history of adolescent idiopathic scoliosis (AIS). Weinstein[57] and others[2,26,28,48,57] have extensively studied the natural 
history of scoliosis and the risk for curve progression. Clear indications for treatment have been established. The risk for curve progression depends on the magnitude of the curve at presentation and the spine's growth pattern. In female adolescents maximum spinal growth occurs near the time of the first menstrual period. The Risser sign[41], which is a useful guide for estimating remaining spinal growth, is based on the appearance and fusion of the iliac apophysis. The apophysis begins to ossify ventrally and progresses in a dorsal direction until the entire iliac wing is capped. The Risser stages range from 0 to 5, with 0 being the stage before which ossification of the iliac apophysis occurs. Stages 1 through 4 correspond to the sequential ossification of each quarter of the iliac crest. The final stage (stage 5) is reached when the apophysis has become closed and fused to the ilium, marking the end of growth.

Surgical radiographs should be obtained in adolescent patients with curves less than $20^{\circ}$ at presentation. Brace therapy in patients with AIS is recommended to minimize curve progression in patients whose curves are greater than $25^{\circ}$ and less than $40^{\circ}$ in patients who have significant growth remaining (Risser stages 0-2). For example, in a girl who is determined to be at Risser stage 0 to 1 and whose curve is measured to be between $20^{\circ}$ and $29^{\circ}$, there is a $70 \%$ chance that the deformity will progress, and these patients should be placed in a brace at presentation. If a patient whose curve is less than $20^{\circ}$, has been followed, then brace therapy is started if progression (an increase of $>5^{\circ}$ ) beyond $20^{\circ}$ is documented (Table 1).

\begin{tabular}{|c|c|}
\hline & $\begin{array}{c}\text { TABLE } 1 \\
\text { IND KATIONS FOR BRACE THERAPY IN PATIENTS WITH IDOPATHIC SCOLOSIS }\end{array}$ \\
\hline & $\begin{array}{l}25-40^{\circ} \text { curves } \& \text { growth remaining } \\
\text { curves progre ssing (increasing } e 5^{\circ} \text { ) abowe } 20^{\circ} \\
\text { thoracolum bosacral orthosis: if curve apex is at T- } 8 \text { or below } \\
\text { modi fied Milwaukee (oervicothoracolumbosacral orthosis): } \\
\text { if apex is above T-8 }\end{array}$ \\
\hline
\end{tabular}

Braces are not indicated for patient whose curves are less than $20^{\circ}$ or for patients approaching the end of growth the growth period (Risser stages 3-5).[4,11,25,29,56,60] Adolescents with curves in excess of $45^{\circ}$ should undergo surgical treatment, because even after skeletal maturity, curves of this magnitude have a high probability of progressing (Fig. 1). Adults whose spinal curvature is greater than $50^{\circ}$ are surgical candidates given a natural history of curve progression of 0.5 to $1.5^{\circ}$ per year with curves of this magnitude. $[6,28,56]$ 


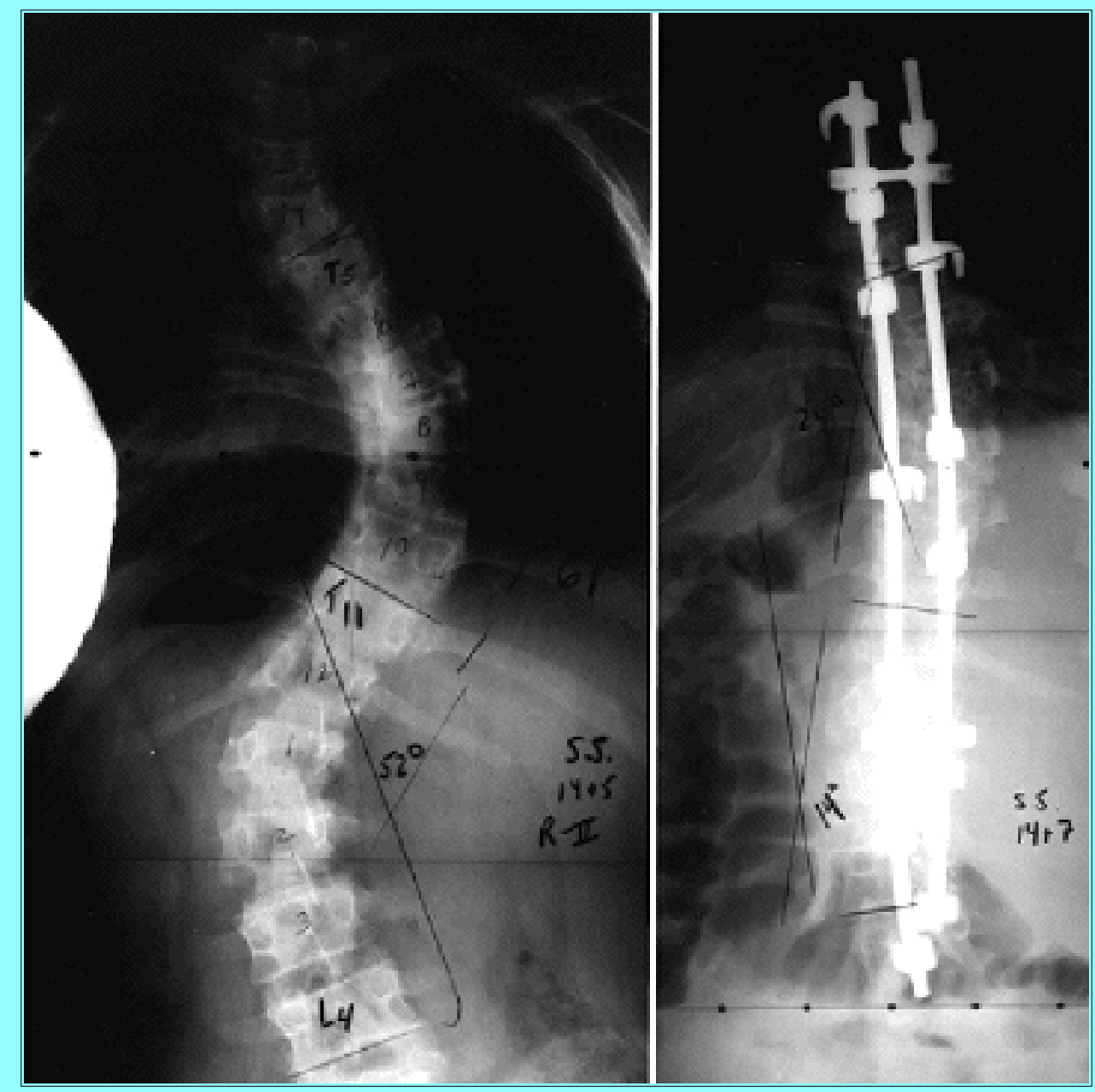

Fig. 1. Radiographs obtained in a 14.5-year old girl with a King type 2 scoliosis who underwent initial managed in a 23/24-hour Boston brace. She had a severe right thoracic rib prominence and progressed rapidly despite brace therapy. Left: Preoperatively her right thoracic curve measured from T5-11 was $61^{\circ}$, and her left lumbar curve measured from T11-L4 was $52^{\circ}$. A thoracoplasty performed for cosmetic purposes, improved correction and obviated the need for a separate bone graft harvest. Right: Initial postoperative films showing correction of her thoracic curve to $24^{\circ}$ and her lumbar curve to $14^{\circ}$. Note the rib removal for the thoracoplasty.

\section{Infants and Juveniles Younger Than 5 Years of Age}

Thoracic scoliosis in children younger than 5-years-old is very rare and differs in several ways from scoliosis in older children. Early-onset scoliosis more commonly affects boys than girls. Pulmonary complications are more common, and curves that develop in infants are commonly left thoracic spine curves (50-75\%). Increased risk of curvature progression is associated with double curves, large curves, and those with significant rotational deformity. Mehta[35] found that risk of progression was related to the rib-vertebral angle difference (RVAD). This angle is formed by a line along the rib head and is perpendicular to the base of the apical vertebra.[35] If the difference between the angles on the concave and convex side exceeds $20^{\circ}$, the progression of the deformity appears to be likely. Obtaining routine magnetic resonance images of brainstem and spinal cord is recommended to exclude central nervous system abnormalities such as syringomyelia in patients aged younger than 8 years who present with a spinal deformity that is greater than $20^{\circ} .[31,43,61]$ 
Because braces and casts are difficult to apply in small children, observation until the spinal deformity reaches $30-40^{\circ}$ is reasonable. Curves that are less than $35^{\circ}$ with an RVAD of less than $20^{\circ}$ respond well to brace therapy whereas curves that are greater than $45^{\circ}$ with an RVAD greater than $20^{\circ}$ have a poor prognosis in terms of avoiding further deformity and surgery. If the early-onset curve fails to be halted by the conservative measures, then surgery should be considered once the spinal deformity exceeds $50^{\circ}$. Spinal instrumentation without fusion ("growth rod" technique) is the preferred technique in patients younger than age 9.[44] This technique involves the insertion of distraction rods along the subfascial space with hooks placed on the end vertebrae. Only the hook sites are stripped of periosteum. Serial distraction is performed every 6 to 9 months by using the ratcheted distraction rod. The patient is protected in a brace at all times, and once adolescence is reached, a formal fusion procedure in which instrumentation is used can be performed. Complications with this technique are common and include hook dislodgment, rod breakage, skin breakdown, and early fusion without bone graft. However, despite the frequent complications, subfascial instrumentation used in the treatment of early-onset or juvenile scoliosis is a sensible alternative to the inevitable cardiopulmonary problems associated with curve progression. As the initial procedure some surgeons perform anterior discectomy over the apical segments, which is followed by placement of posterior subcutaneous rods. An anterior discectomy is required to correct the spinal deformity in more severe curves and in the presence of a lordotic thoracic spine. If a young child undergoes a fusion procedure, it is necessary to perform both and anterior and posterior spinal fusion to prevent the development of the crankshaft phenomenon.

\section{SURGICAL APPROACHES}

Whether the surgical technique is anterior, posterior, or a combined anterior-posterior approach, the desired result is the same: bony fusion to arrest the progression of the curve, restoration of normal coronal and sagittal balance and functional, and a pleasing cosmetic appearance (Table 2).

\begin{tabular}{|l|}
\hline \multicolumn{1}{c|}{ TABLE 2 } \\
GoALS OF SPINAL DEFORMTY CORRECTION \\
\hline \hline normal coronal \& sagittal alignment \\
shoulders level \& head centered over pelvis \\
preservation of as many motion segments as possite \\
fusion \& arrest of cur've progression \\
acoeptable cosmesis \\
pain relief
\end{tabular}

\section{Posterior Approach}

The posterior approach for fusion in patients with idiopathic scoliosis is the gold standard with which all other methods must be compared.[3,5-7,21,22,27,34,40,42,49] It has a proven track record of success, with excellent fusion rates and good curve correction (Table 3 ). 


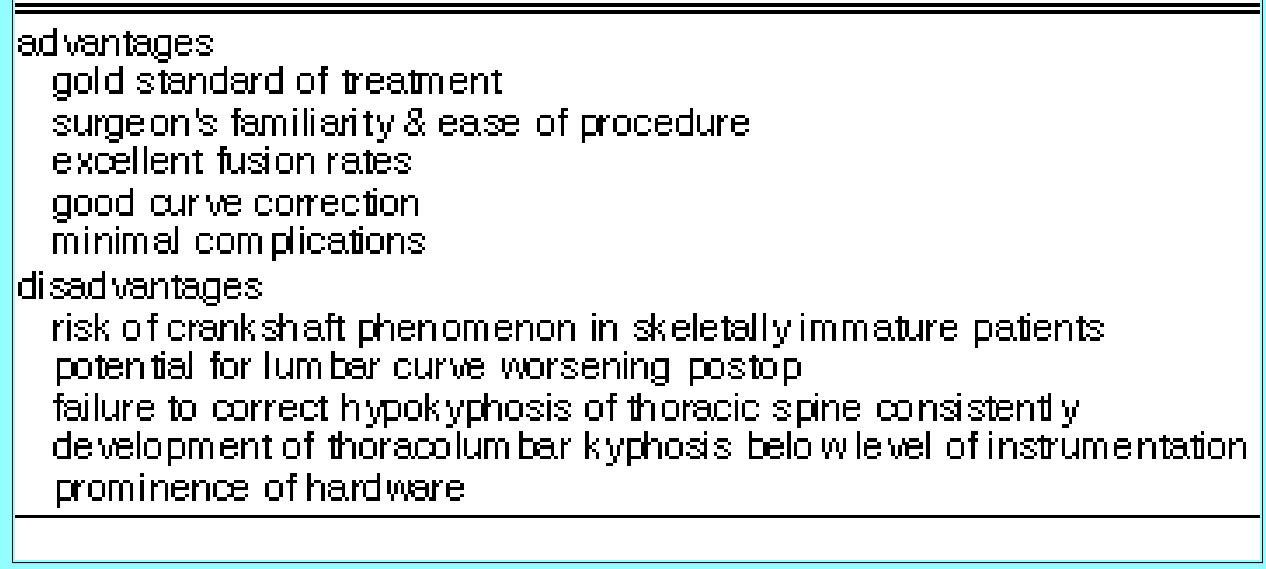

Posterior spinal instrumentation used to correct of deformity has evolved rapidly since the introduction of the distraction rods and hooks by Harrington in 1960.[21,22] His system was the first to achieve some fixation with some correction of deformity. Despite the usefulness of his distraction rod, patients needed to be placed in a cast brace postoperatively to prevent rod dislodgment and to maintain alignment. Frequently, surgery required distraction into the lumbar spine, which caused loss of lordosis in the sagittal plane and resulted in some patients developing a debilitating "flat-back" syndrome. The next advance was the use of the Luque rod with which sublaminar wires were used to achieve segmental fixation; however, some patients developed neurological deficits related to the passage of the sublaminar wires. This system is still frequently used for the treatment of neuromuscular scoliosis (Fig. 2).
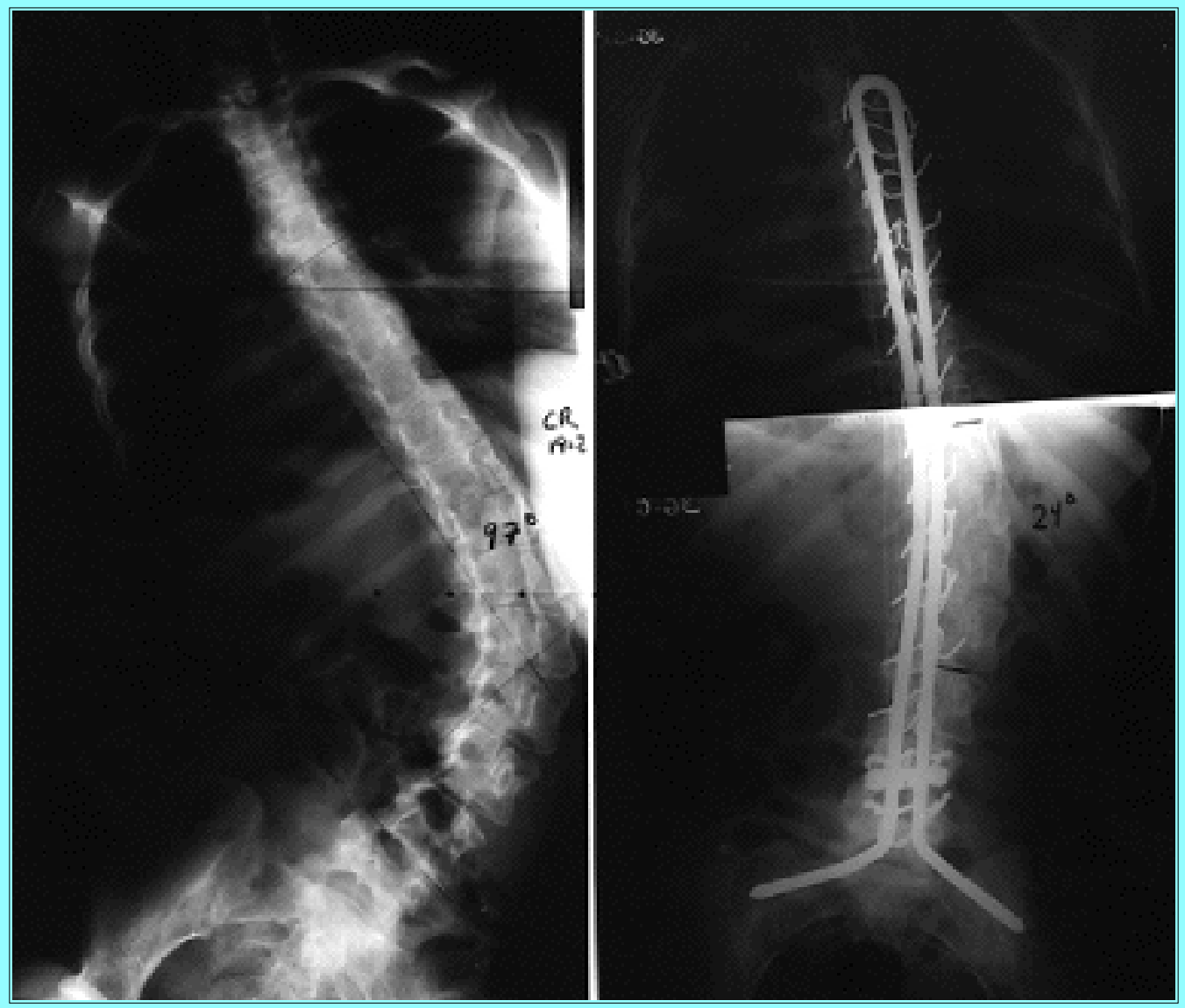

Fig. 2. Radiographs obtained in a 19.2-year-old woman whose spastic quadriplegic cerebral palsy was secondary to microcephaly caused by a perinatal cytomegalovirus infection. Left: 
Her right thoracolumbar curve measured $97^{\circ}$, and she suffered from progressive pulmonary compromise with recurrent pneumonias. "Push-pull" radiographs showed that her curve was still flexible and corrected to $34^{\circ}$ with leveling of her pelvis. Right: She underwent

Luque-Galveston posterior segmental instrumentation and fusion with a $24^{\circ}$ curve.

More recently, several systems have been developed using a series of hooks, screws, and rods to achieve better segmental fixation and to allow compression and distraction across various parts of the curve. These systems have the advantage of not requiring the patient to wear a brace postoperatively. In addition, by rotating the rod appropriately, better control of the sagittal curve can be obtained and lumbar levels may be spared. The prototype for these systems, still used today, is the Cotrel-Dubousset (CD) system.[27] In the CD system several options for segmental anchoring exist: hooks, wires, or pedicle screws. Hooks vary in width, blade angle, and blade depth to accommodate the changes in canal dimension throughout the length of the spine. A bifid hook may be used to gain purchase on the thoracic pedicles, whereas in other areas of the spine the hook blade is flat (Fig. 3). The hook bodies may be opened or closed. The open-hook design allows the rod to be placed after hooks are positioned on the strategic vertebrae. Rod diameters and strength can be varied to accommodate differences in body habitus. Quarter-inch rods $(6.5 \mathrm{~mm})$ are used in most cases; however in small adolescents or children, 3/16-inch rods $(5.0 \mathrm{~mm})$ are available for use in lower-profile hook systems to reduce hardware prominence. The strength will vary inversely with rod diameter, but the manufacturing technique and metal type can also influence strength as well. Although stainless steel is most commonly used in rod construction, titanium, which is stronger, lighter, and more expensive, has become readily available. Because titanium has the advantage of being compatible with MR imaging, its use in conjunction with canal decompression may be preferred. However, titanium rods are more difficult to contour and are more prone to break if repeatedly bent or notched. 


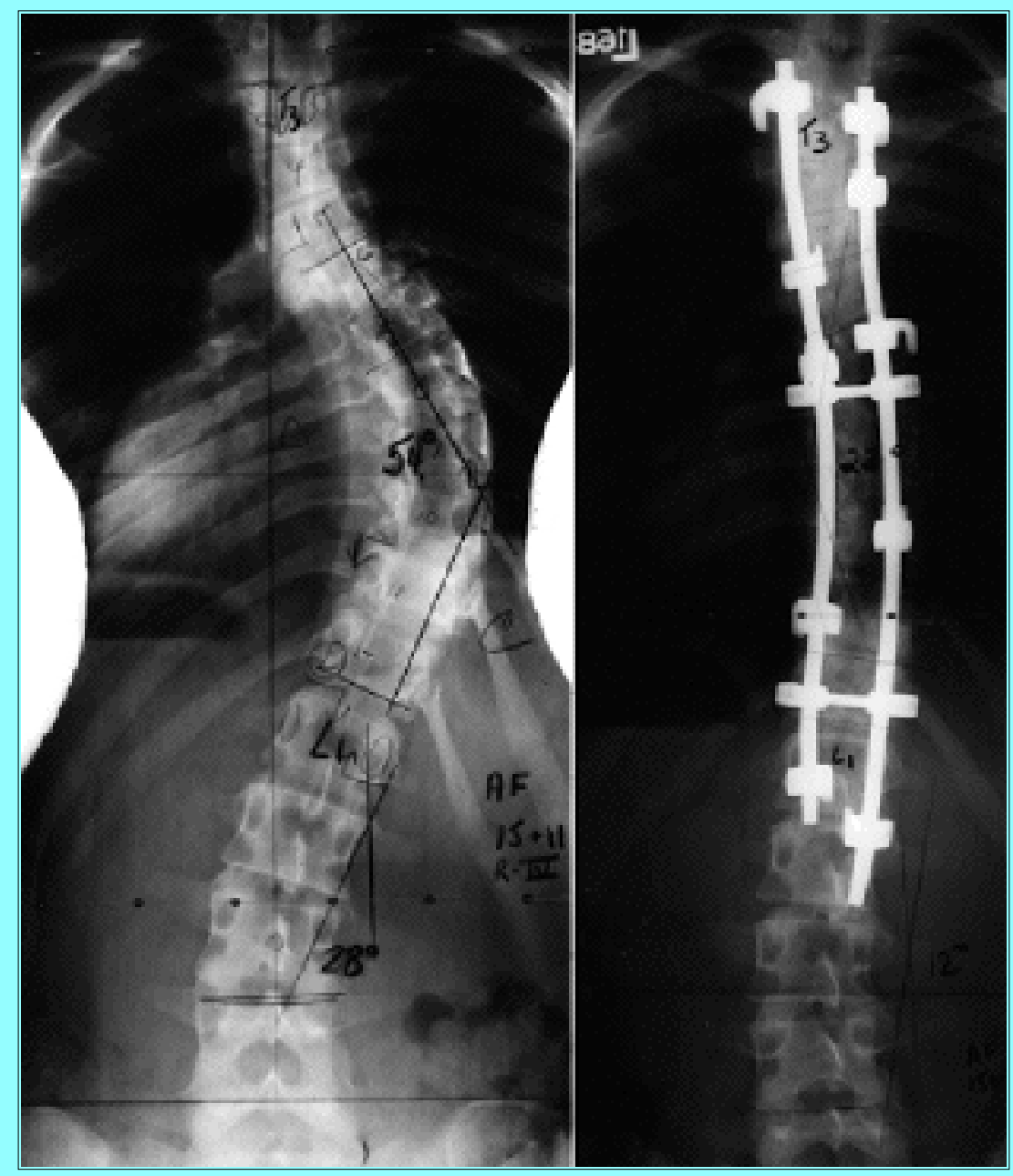

Fig. 3. Radiographs obtained in a 15.11-year-old girl whose spinal growth was deemed Risser stage 4. Left: She suffered from a right thoracic King type 2 scoliosis curve pattern that measured $54^{\circ}$ and a left lumbar curve that measured $28^{\circ}$. The curve improved to $43^{\circ}$ on right side bending and increased to $62^{\circ}$ on left side bending. She underwent posterior segmental instrumentation and fusion from T3-L1 with thoracoplasty. Right:

Postoperatively a $20^{\circ}$ curve was seen between T5-12, and the lumbar curve measured $12^{\circ}$.

Despite the advantages of the newer systems, the posterior approach remains problematic, particularly for thoracolumbar curves (Table 3). One major deficiency associated with posterior fusion alone in which the CD or Harrington system is used is the development of the crankshaft phenomenon. The crankshaft phenomenon, first described by Dubousset, et al.,[15] occurs when the anterior column of the spine continues to grow in the presence of a solid posterior fusion. The spine is unable to continue to elongate due to the tethering effect of the posterior fusion mass, and continued anterior growth causes sagittal deformity. The resultant deformity is always concave in relation to the side of the fusion mass and convex in relation to the side of the continued growth, producing a lordoscoliosis with rotation in the direction of the original rotatory deformity. This process has been used to explain curve progression in preadolescent patients $[15,44,45]$ who have undergone posterior fusion in which instumentation is placed. The main risk factor is skeletal immaturity when considerable spinal growth potential remains. This is determined based on the patient's Risser stage (stages 0-2), status of triradial cartilage (open), and amount of predicted residual curve $\left(>30^{\circ}\right)$ after posterior correction. In a retrospective review of 86 immature patients undergoing posterior thoracic fusion for idiopathic scoliosis, Roberto, et al.,[42] found that $75 \%$ of patients who were Tanner Stage 1 with open triradial cartilages developed the crankshaft effect (progression of $>10^{\circ}$ ) compared with no patients who were Tanner Stage 4 (unpublished data). 
Because the crankshaft phenomenon is difficult to correct, it is recommended that patients with the aforementioned risk factors either undergo placement of spinal instrumentation without fusion and serial distraction as described previously or undergo a combined anterior-posterior fusion procedure.

A second problem associated with posterior systems is lumbar spine curve decompensation (worsening of the concomitant lumbar curve after thoracic fusion), $[8,33,52]$ which is usually caused when the fusion procedure fails to extend low enough in the lumbar spine in an attempt to save a lumbar level. Posterior systems also fail consistently to correct hypokyphosis of the spine.[3,44] More importantly, whereas newer systems such as the CD have more correctional effect in the sagittal plane than the older Harrington system, thoracolumbar kyphosis has been reported below the level of the fusion, and in fusion procedures that extend into the lumbar spine the potential for flat-back syndrome exists.[3,12,31] Additionally, the CD system has a high profile and is often prominent under the skin, occasionally requiring revision. There is recent data to suggest that these systems may be at risk for delayed infection and loosening.[39,59]

\section{Anterior Approach}

At approximately the same time that Harrington was developing posterior instrumentation for use in correction of scoliosis in the United States, Dwyer was developing the first anterior system in Australia.[16] Dwyer reasoned that better correction could be achieved by placing instrumentation in the vertebral bodies after anterior release and discectomy were performed. His anterior approach and the instrumentation (vertebral body screw, staple, and cable construct) were the prototype for development of subsequent systems. A newer anterior-approach system for the placement of instrumentation in the treatment of scoliotic deformities was proposed by Zielke (as discussed in Halm, et al.,[20] and Lowe and Peters[30]) who substituted a single threaded rod and nuts for the cable and introduced a derotator to correct rotation. The rod rotator and the rigidity of the rods were thought to minimize the associated kyphosis that was common when using Dwyer's cables. Problems with hardware failure were encountered with this system. Newer anterior instrumentation systems have been proposed by Kaneda et al.,[24] and Hopf, et al.,[23] in which two screws and two-rod systems are used. By placing one screw anteriorly and one screw posteriorly, they have been able to improve spinal lordosis by performing distraction on the more anterior rod and compressing the more posterior rod. As an adjunct to anterior instrumentation, the use of cages packed with rib graft that provide structural anterior column support has become more popular.

The advantages and disadvantages of using anterior instrumentation are listed in Table 4 and include better curve correction, particularly in cases of inflexible thoracic curves. Lenke, et al.,[27] have studied the level of correction obtained in either anterior or posterior fusion. An overall correction rate of 58\% was achieved in the anterior group, whereas only a 38\% correction rate was realized in the posterior group. In anterior-group patients better spontaneous correction of the lumbar curve was demonstrated than in posterior group patients (56\% and 37\%, respectively). For King type 2[26] curves the correction was more dramatic: $67 \%$ in the anterior group compared with $27 \%$ in the posterior group. The theoretical advantage of anterior instrumentation systems is that they at offer a mechanical advantage over posterior instrumentation in that they achieve large curve corrections. In studies up to $90 \%$ of the rotational stability of the spine has been shown to exist in the anterior two-thirds of the vertebral body and disc, which is why an anterior release is such an effective maneuver prior to fusion. In addition, an anterior approach allows for a larger moment arm for correction. This is because the instantaneous axix of rotation is located near the spinal canal. A sublaminar hook placed from a posterior approach will have a 
short moment arm to the instantaneous axix of rotation. A screw placed in the vertebral body from an anterior approach, however, will have a much larger moment arm and will achieve greater correction. Another advantage is that many patients with thoracic scoliosis have a loss of normal thoracic kyphosis (hypokyphosis), and the anterior systems are, by nature, kyphogenic and are better at restoring normal alignment. Patients with severe thoracic lordosis have a rare but particularly dangerous deformity in which pulmonary function is compromised as the deformity progresses. This is an indication for isolated anterior fusion.

\begin{tabular}{|c|}
\hline $\begin{array}{c}\text { TABLE } 4 \\
\text { ADYANTAGES AND DISADVANTAGES OF ANTERIOR FUSON }\end{array}$ \\
\hline $\begin{array}{l}\text { advantages } \\
\text { better cur ce correction (tiomechanical advantage) } \\
\text { better correction of thoracic hypok yphosis } \\
\text { prevention of crankshaft phenomenon } \\
\text { reduced risk of lumbar curwe decom pensation } \\
\text { "selecti ve" thoracic fusion alows saving of distal segm ents } \\
\text { potential for decreased low back pain by saving le vels } \\
\text { no prom inent hardware. } \\
\text { disadvantages } \\
\text { higher pseudarthrosis rates } \\
\text { increased hardware failure } \\
\text { potential for hyperkyphosis }\end{array}$ \\
\hline
\end{tabular}

In a prospective series of 178 patients, Betz and coworkers[3] examined the results of anterior and posterior instrumentation in patients thoracic AIS. One group of 78 patients underwent placement of anterior instrumentation with vertebral body screws and flexible rods, and 100 patients underwent posterior spinal fusion in which multisegmented hook systems were used. Postoperatively the coronal correction and balance were equal in both groups despite the fact that in the anterior group the majority of the curves (97\%) were fused short to L-1 whereas in the posterior group the fusions were longer (only $18 \%$ fused short to L-1) saving an average of 2.5 lumbar levels. In patients with preoperatively documented kyphosis of less than $20^{\circ}$ the better correction was achieved in the sagittal plane in the anterior group than in the posterior group.

These anterior systems are ideally suited for the treatment of lumbar or thoracolumbar scoliosis in which a minimal or flexible thoracic curve exists (Fig. 4). Correction of the deformity can be obtained with the sparing of lumbar levels. It is important in fusions involving the thoracolumbar spine to maintain adequate lordosis. As stated previously, anterior systems are, by nature, kyphogenic, and it is important to maintain intervertebral height through either rib autograft or placement of autograft-packed anterior cages. Failure to maintain lordosis puts the patient at risk for flat-back syndrome. 

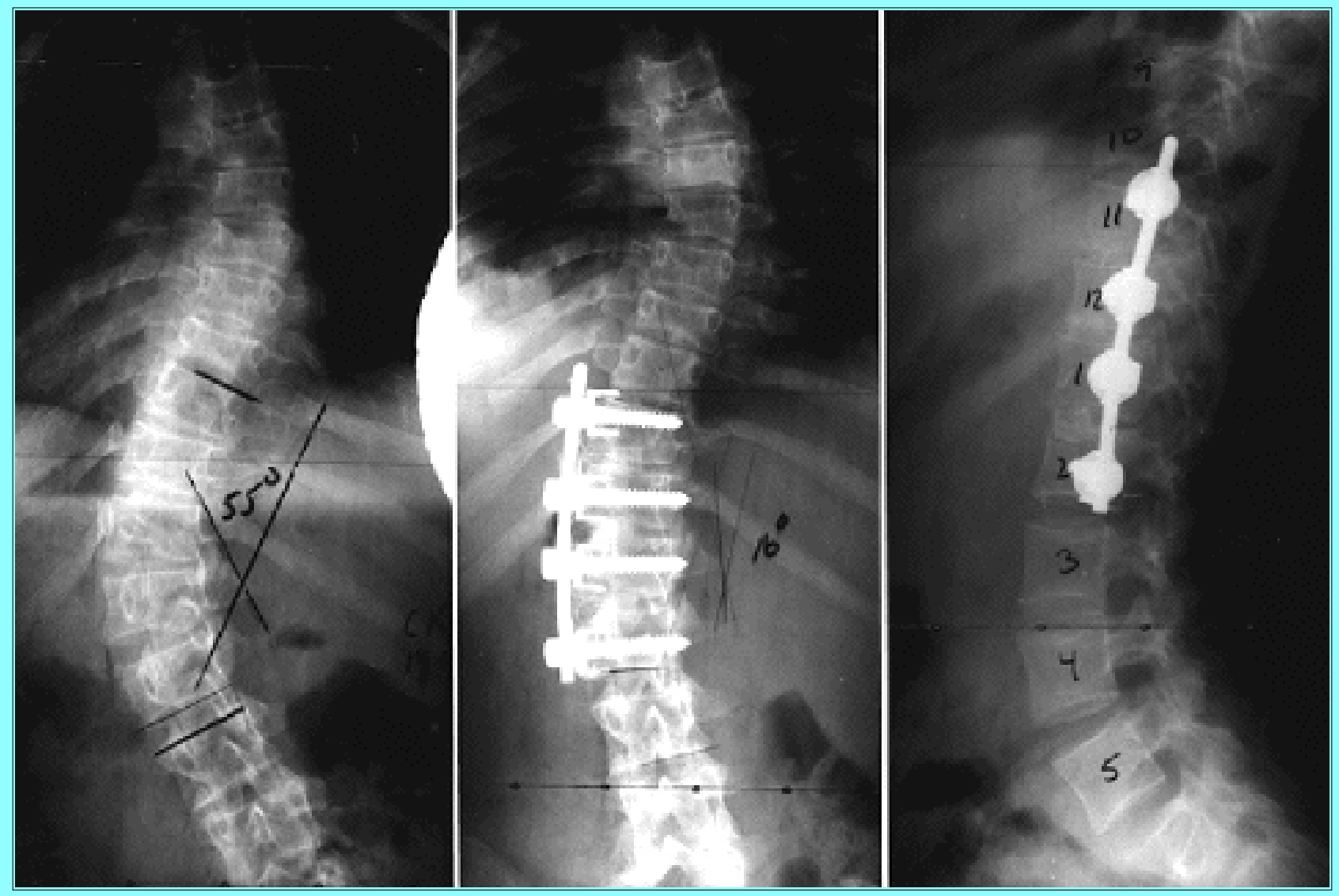

Fig. 4. Radiograph obtained in a 14.8-year-old girl with a history of osteogenesis imperfecta tarda. Left: The left thoracolumbar scoliosis curve measured $54^{\circ}$ from T10-L3 with a compensatory a right-sided thoracic curve that measured $37^{\circ}$ from T2-10. She underwent an anterolateral approach to the lumbar spine in which segmental instrumentation was placed from T11-L2 to spare lumbar levels. Despite her underlying bone disease the instrumentation was successful. Center and Right: The postoperative thoracolumbar curve measured $16^{\circ}$ and her thoracic curve improved to $30^{\circ}$ with good maintenance of lumbar lordosis.

\section{Minimal Complications}

Despite the recent enthusiasm for treating thoracic scoliosis via an anterior approach, there are still significant problems with anterior systems that need to be addressed[18,52,58] (Table 4). In addition to the possibility of pulmonary compromise and other deficits related to thoracotomy, there has been a higher pseudarthrosis rate, the potential for hyperkyphosis, and more hardware failure than in patients in whom posterior systems are used. Betz and coworkers[3] compared anterior and posterior systems and noted that the incidence of pseudarthrosis was significantly greater in the anterior than posterior group (5\% and $1 \%$, respectively), as was implant breakage (31\% and $1 \%$, respectively).[3] These authors also found that if the thoracic kyphosis documented preoperatively was greater than $20^{\circ}$, then patients in the anterior group fared less well. Anterior instrumentation and arthrodesis frequently resulted in overcorrection in the sagittal plane that resulted in the development of hyperkyphosis in $40 \%$ of the patients.

\section{Combined Anterior-Posterior Approach}

The combined approach has several well-defined indications for which neither anterior nor posterior 
approach alone will suffice[1,5,9,10,14,17,32,38,44,47] (Table 5). The advantage of approaching the patient anteriorly prior to posterior fusion is that by performing an anterior-release procedure with or without the use of instrumentation, a much greater degree of correction can be achieved than when performing anterior or posterior approaches alone. Indication for the combined anterior-posterior procedure include patients of high risk for developing crankshaft phenomenon; large spinal curves (in excess of $75^{\circ}$ ) in skeletally mature or immature patients; excessively rigid spinal curves not shown to correct on side-bending X-ray films to less than $60^{\circ}$ (Fig. 5); fixed thoracic kyphosis; and any fusion extended to the sacrum in an adult patient.

\begin{tabular}{|c|}
\hline $\begin{array}{l}\text { TABLE } 5 \\
\text { IND KATIONS FOR COMBNED ANTERIOR-POSTERIOR PROCEDURES }\end{array}$ \\
\hline 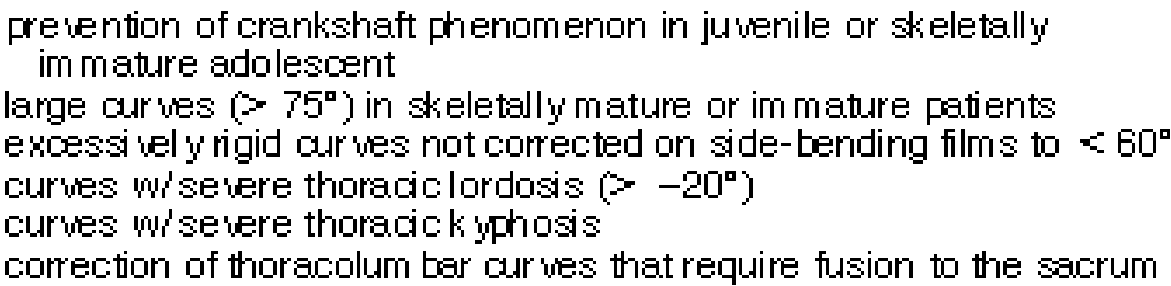 \\
\hline
\end{tabular}
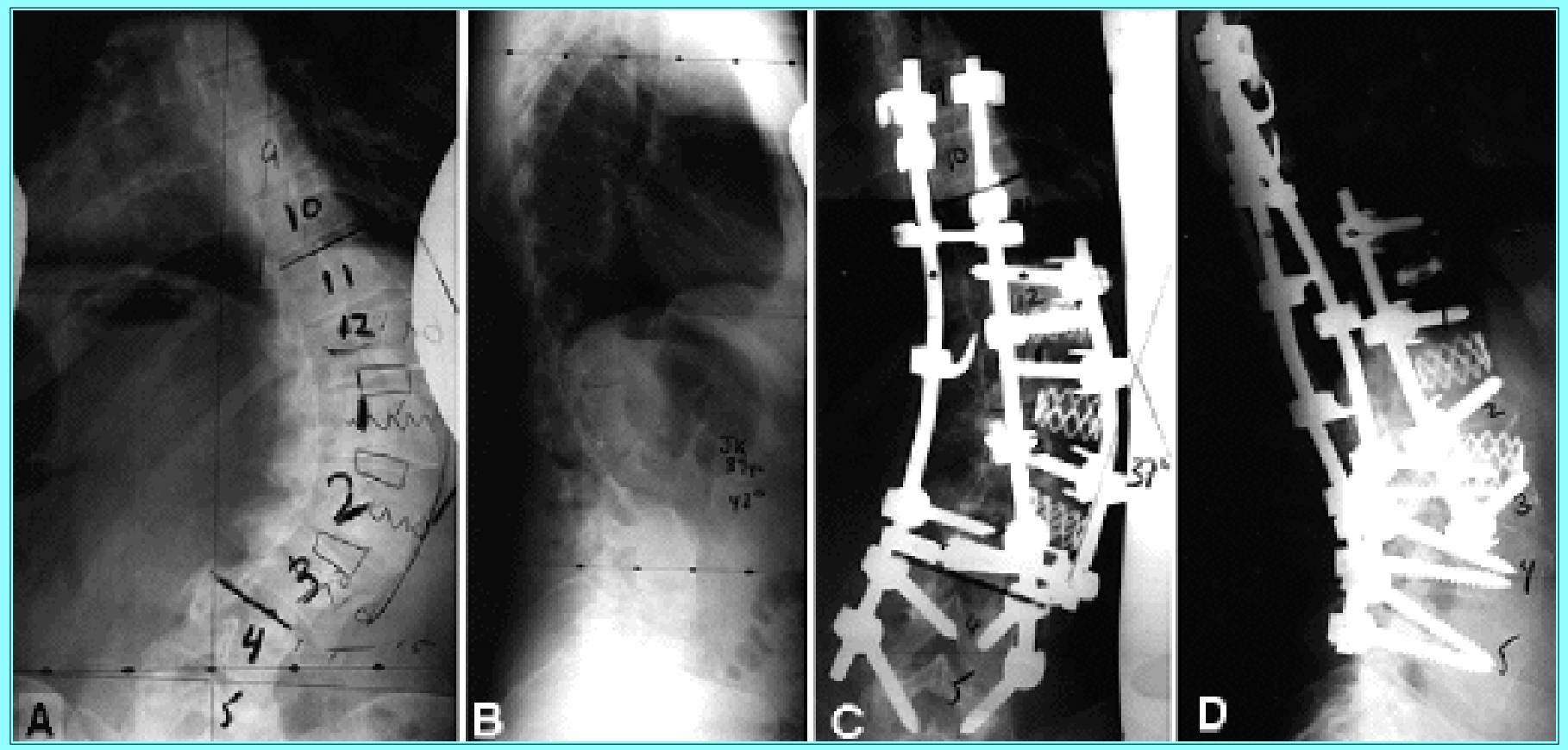

Fig. 5. Radiographs obtained in a 39-year-old woman in whom an initial diagnosis of scoliosis was made at age 12.6 years and who was treated with a Milwaukee brace. The patient did reasonably well through adolescence and suffered only occasional back symptoms, but she began to experience progressively worsening pain, especially after two pregnancies. Preoperative radiographs (A, B) revealed a $62^{\circ}$ lumbar curve measured from T11-L4 and a $28^{\circ}$ compensatory thoracic curve from T11-T5. She suffered severe back and radicular pain. On side-bending radiographs the deformity was corrected to $48^{\circ}$ on right-side bending and the curve remained at $59^{\circ}$ on left-side bending. There was $12 \mathrm{~mm}$ of lateral subluxation of L-3 on L-4 that corrected minimally with side bending. She required a combined anterior-posterior approach because of the curve's magnitude and stiffness. Postoperatively her curve measured $37^{\circ}$ and the lateral subluxation of L-3 on L-4 was decreased to $4 \mathrm{~mm}(\mathrm{C}, \mathrm{D})$. Note the use of interbody cages packed with rib autograft to 
maintain the anterior disc height and preserve normal lumbar lordosis.

The risk factors for developing crankshaft phenomenon include a Risser stage of 0 or 1 , Tanner Stage less than 2 , open triradial cartilages, and apical rotation over $30^{\circ}[42,45]$ (Fig. 6). In cases with double curves in which a lumbar component needs to be fused to the sacrum, the anterior exposure allows the lumbar spine to be distracted anteriorly, normal lordosis to be maintained, and release of focal kyphosis of greater than $50^{\circ}$ in the thoracic spine (Fig. 7). Generally in patients with significant kyphosis anterior structural support is required in addition to anterior release and bone grafting to minimize loss of correction. In patients with severe kyphosis that causes neurological deficit, anterior decompressive surgery of the spinal cord is required in conjunction with the anterior and posterior reconstruction. A deformity with a severe thoracic lordosis $\left(>-20^{\circ}\right)$ usually requires correction by staged anterior wedge osteotomies, followed by posterior instrumentation and fusion. Complications, including paralysis and death, frequently occur when performing corrective surgery for severe thoracic lordoscoliosis. Only surgeons very experienced in treating deformity of the spine should consider undertaking this type of surgery.
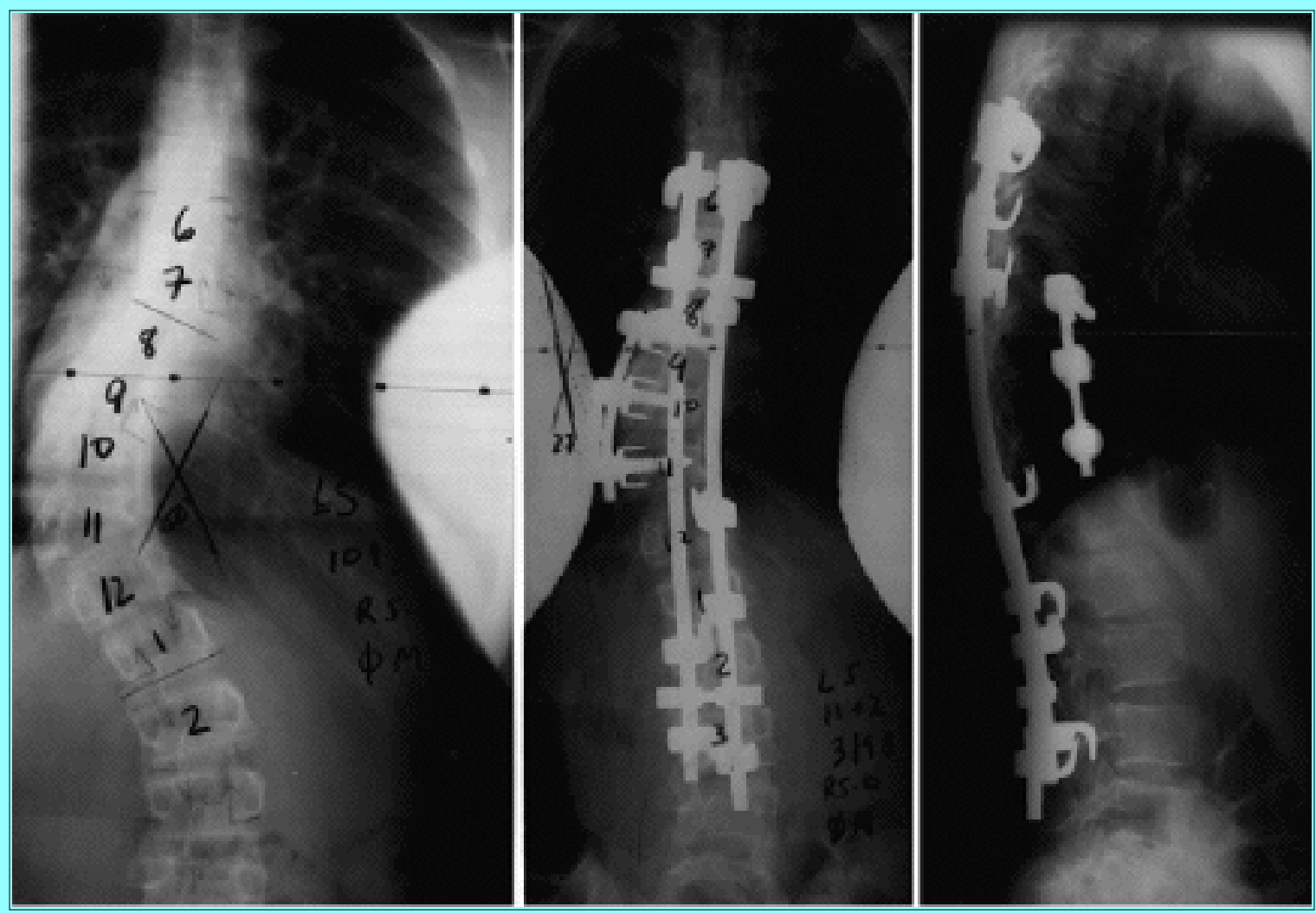

Fig. 6. Radiographs obtained in an 11.2-year-old girl with dysplastic left-sided thoracic scoliosis secondary to neurofibromatosis. Preoperative magnetic resonance imaging (not shown) revealed multiple intradural neurofibromas and left-sided dural ectasias. Left: Her deformity progressed despite brace therapy to a curve of $50^{\circ}$. She was skeletally immature (Risser stage -0, open triradiate cartilages, and Tanner Stage -0) and was at risk for developing the crankshaft phenomenon if she was treated solely via a posterior approach. Center: She subsequently underwent laminectomy, tumor resection, posterior segmental instrumented fusion. Right: A second-stage thoracotomy with anterior fusion and instrumentation was performed to reduce the risk of the crankshaft deformity. Anteroposterior (center) and lateral (right) postoperative films show good correction with maintenance of normal sagittal profile. 


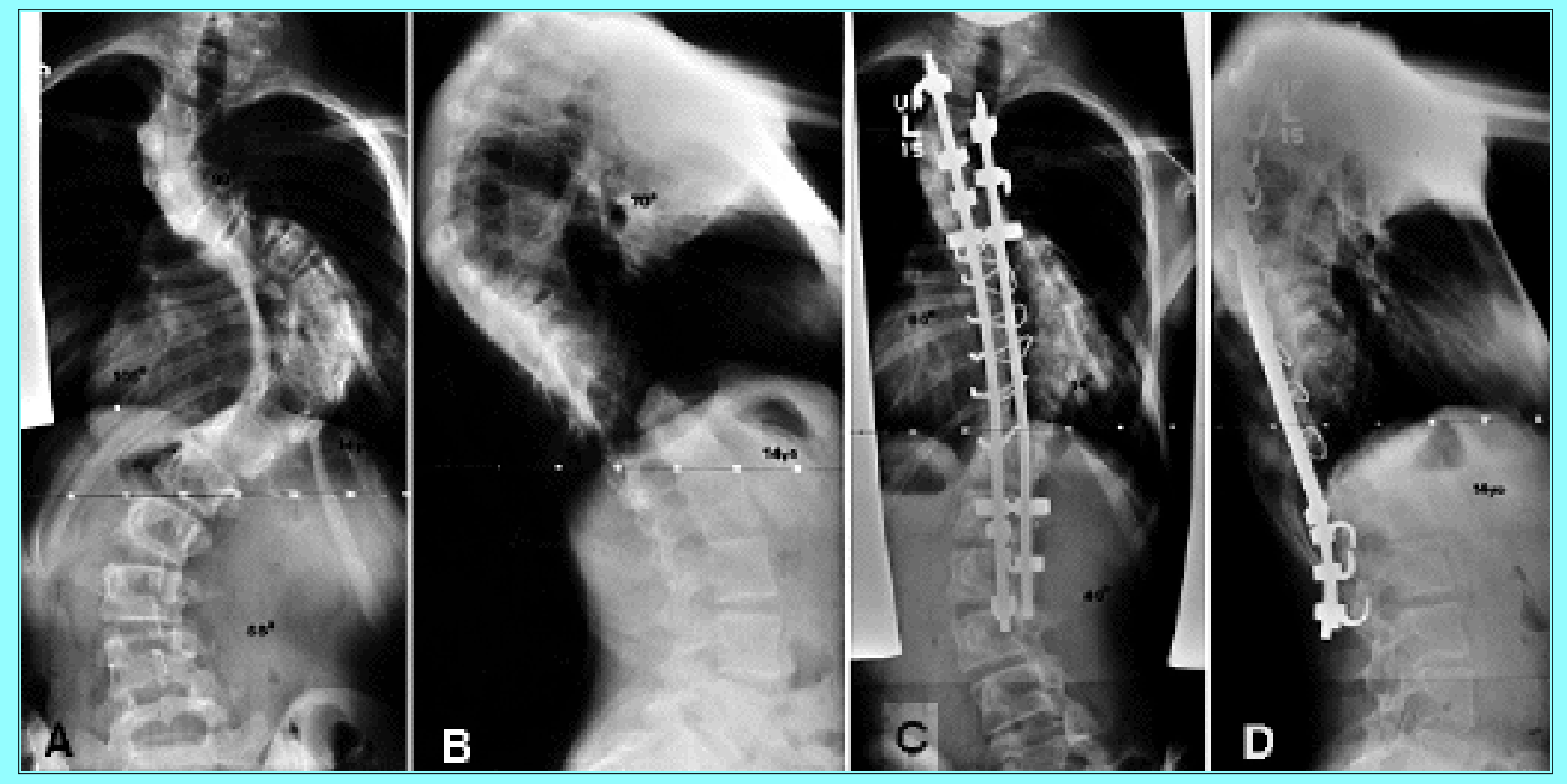

Fig. 7. Radiographs obtained in a 14-year-old girl (Risser stage 4) who presented with a severe right thoracolumbar kyphoscoliosis. The primary thoracic curve measured $105^{\circ}$ with compensatory thoracic and lumbar curves of $90^{\circ}$ and $58^{\circ}$; there is $70^{\circ}$ of thoracic kyphosis (A and B). These curves moved minimally on dynamic studies. She underwent anterior release and posterior segmental instrumentation and fusion in a same-day combined procedure. Postoperative radiographs showed the thoracic curve improved to $60^{\circ}$ and the thoracic kyphosis improved to $30^{\circ}$ (C and D).

\section{SURGICAL TECHNIQUE}

Prior to any procedure thoughtful planning of the proposed surgery is mandatory (Table 6). There are a number of considerations when choosing what vertebral levels will be fused and what approaches will be performed in which order. In addition, careful attention must be paid to intraoperative management (Table 7).

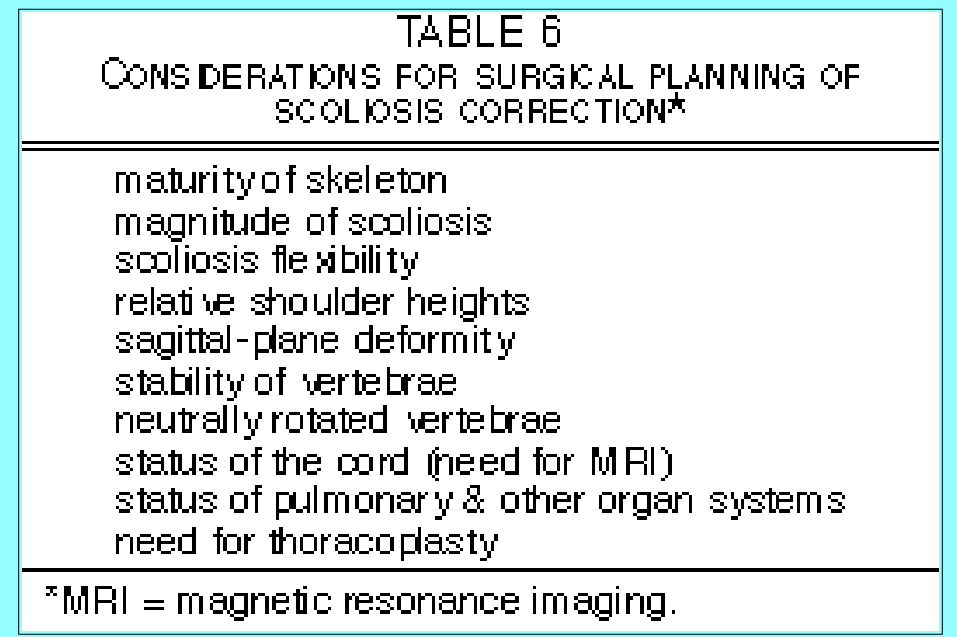


positioning to relieve pressure \& provide abdominal freedom; awoidance of peripheral nerwe injury

monitoring arterial, peripheral, \& central lines

Foley catheter

spinal cond ewoked potential monitoring

use of cell-saver system

controlled hypotension

antitiotic ooverage

The combined anterior-posterior approach can be performed as a single operation or as a staged procedure. Traditionally, the anterior procedure was performed first, and the patient was allowed to recover 1 to 2 weeks prior to the undergoing posterior procedure. Complication rates from these procedures have been very high, ranging from 33 to $75 \%$.[1,9,17,38] Mandelbaum and associates[32] have demonstrated that after the first procedure, patients are nutritionally deficient and in a state of catabolism prior to undergoing the second procedure; these factors make these operations prone to complications. In recently studies by Shufflebarger,[46] Powell, et al.,[38], and Saer, et al., (unpublished data) the efficacy of the one-stage combined procedure has been demonstrated. Patients have shorter hospital stays and lower costs, sustain fewer complications including fewer wound infections, and less blood loss. An additional benefit is that patients and their families desire to have the procedure performed in one setting. We therefore undertake the single-stage combined anterior-posterior approach almost exclusively when the total procedure can be performed in 12 hours or less.

We generally require the assistance of an experienced pediatric or thoracic surgeon to assist with the exposure for anterior procedures. Preoperatively all patients are requested to donate two units of packed red cells. A cell-saver system is routinely used, and great care is taken at surgery to wring out all sponges and to avoid blood loss. It is therefore a rarity for a patient to ever require blood from the blood bank. All procedures are planned using somatosenory evoked potential monitoring and the possibility of a wake-up test is explained to the family.[19,37] Preoperative antibiotic medications are given and then provided as appropriate every 4 hours during the procedure. The patient is placed in the lateral decubitus position, convex side up. Double major spinal deformities may require two separate surgical approaches: a thoracotomy for the thoracic curve and a thoracoabdominal approach on the contralateral side for the thoracolumbar or lumbar curve.

In patients with thoracic scoliosis a standard thoracotomy is generally required.[4,24,44,53] The incision and rib resection are performed on the rib of the vertebrae one or two segments above where the most rostral instrumentation is to be placed. In typical idiopathic scoliosis patients this is usually the fifth or sixth rib. Longer thoracic curves occasionally require a second, more caudal thoracotomy based on the 11 th rib by using the same or a separate incision. A typical thoracoabdominal approach requires that the incision be made from the angle of the rib to be resected, posteriorly to the costal cartilage of the 10th rib, and then angled anteriorly and inferiorly. The required number of lumbar segments to be exposed will determine the length of the abdominal incision. The thoracic portion of the deformity is treated via the chest cavity and the lumbar portion via a retroperitoneal approach. The vertebral discs to be spanned by the instrumentation must be exposed sufficiently to allow complete removal back to the posterior longitudinal ligament. Therefore, the psoas muscle is mobilized in the lumbar spine, and the segmental vessels frequently need to be ligated to achieve the exposure. A large Cobb elevator is used carefully to 
scrape the endplates clean of any remaining disc material. Following discectomy, the vertebral endplates are decorticated to expose bleeding surfaces for fusion. Gel foam is used temporarily to control bleeding while the implants are inserted. It is important to take the rib heads and the associated ligament-capsular structures down to achieve effective destabilization of the rib. The vertebral-body screws vary in diameter from 5.5 to $7.0 \mathrm{~mm}$, and pullout strength increases in proportion to thread depth (diameter). To maximize holding power, the screws are inserted in the midlateral point of the vertebral body until a thread penetrates the far cortex. Screw length can be measured before insertion and the direction judged by looking across the disc space. With proper exposure, a finger can be placed on the far side of the vertebral body to avoid prominence of the tip. The end screws are placed first and followed by the intermediate screws for ease of alignment. The rod is placed within the screw heads and rotated to convert the scoliosis into lordosis by a rod-rotation maneuver. After rotation, each disc space will visibly open anteriorly and should be filled with bone graft after some temporary distraction between the screws. Rib graft harvested at the time of the surgical approach is the ideal bone source. Anterior titanium cages filled with bone graft can be used to improve sagittal-plane correction and to remove stress from the rod-screw construct (Fig. 5). Vertebral compression and definitive tightening of the screws to the rod are then performed to stabilize the construct. The rods vary from 4.8 to $6.5 \mathrm{~mm}$ in diameter and may be strong enough so that a postoperative brace or cast brace is not needed.

\section{Posterior Approach}

Following the anterior release, the patient is positioned on a four-post scoliosis frame or Jackson table that allows the abdomen to hang freely, thus reducing venous pressure and bleeding. The entire back and iliac crests are prepared within the surgical field. Tissue dissection is the same along the entire length of the posterior spine, but the orientation and configuration of the vertebrae differ and must be studied. The spine is exposed to the tips of the transverse processes. The principles of posterior fusion are the very same as those in a routine fusion procedure. Autologous bone is the gold standard for fusion substrates. Ample fusion material is usually obtained from the ribs if a thoracoplasty is indicated. Otherwise, the posterior iliac crest should be harvested to ensure a large amount of usable bone. The transverse processes are decorticated, and generous facetectomies are performed at the levels to be fused. It is important to perform the facetectomies and to graft all uninstrumented levels before placing the rods in position or access to the facets will be blocked. If a hook-and-rod system is being used, hook sites are prepared after obtaining exposure and prior to decortication to minimize blood loss.

As posterior-approach spinal systems have been developed, the following principles have evolved for selection of levels to undergo instrumentation and fusion: 1) instrumentation should start and end in the stable zone; 2) ending instrumentation at a junctional zone between kyphotic and lordotic curve should be avoided; and 3) insertion of the concave rod should be done first if the major curve is lordotic, and distractive forces should be applied. Conversely, the convex rod is inserted first and hooks compressed, if correction of a kyphotic primary curve is desired. With posterior systems axial correction can be achieved using segmental fixation and cantilevering the rod into the hooks or by using a rod derotation maneuver. In all cases, attempts are made to correct frontal and sagittal alignment. As stated previously, meticulous facetectomy, decortication, and autologous bone grafting are essential to achieve lasting correction of spinal deformities. Hardware loosening, loss of correction, pain, and rod breakage are potential problems if fusion is not successfully achieved.

\section{Thoracoplasty}


In any consideration of surgical correction of thoracic scoliosis, the topic of thoracoplasty should be discussed with the patient.[47] Despite the attention given to the frontal-plane deformity, patients with scoliosis are often most concerned with the resultant breast and rib asymmetry. Deformity of the chest wall results from the transverse plane malrotation and rib dysplasia associated with scoliosis. Typically, a right posterior rib prominence is seen as well as anterior projections of the left chest. Obviously, these chest wall and rib changes will be more dramatic in patients with early-onset scoliosis.

Thoracoplasty, as performed today, is the surgical technique by which the prominent rib sections on the convex side of the thoracic deformity are removed. The procedure was performed, along with posterior fusion, for treatment of idiopathic scoliosis decades ago. Currently, hesitation in performing the procedure stems from the reported deterioration in pulmonary function demonstrated in some patients postoperatively. Owen and associates[36] have found a significant reduction in pulmonary function in a group of patients who underwent thoracoplasty in which Harrington rods were used compared with a group of patients in whom posterior instrumentation alone was used. Therefore, baseline pulmonary function should be monitored before thoracoplasty is performed, and the procedure should not be undertaken if forced vital capacity is less than $60 \%$ of predicted values. Adult patients are much more prone to significant pulmonary compromise following thoracoplasty.

Surgery may be performed via an anterior (internal) or posterior approach.[47,50] The posterior approach is more common, and when undertaken in conjunction with a spinal fusion, it is performed via the same skin incision. The midline incision is created and elevated to the posterior axillary line to expose the rib. On the average, seven ribs are excised from the posterior axillary line to the junction with the transverse process. The excised ribs are used for bone graft material if the procedure is undertaken along with spinal fusion. The rib is exposed by subperiosteal dissection so that the pleura is not violated. However, if the pleura is inadvertently opened, it may be sewn over using a red-robin catheter, which is pulled and aspirated prior to the tying the last suture. This maneuver may avoid the need for a chest tube postoperatively.

Thoracoplasty is performed primarily to address the cosmetic deformity produced by the convex rib prominence. Therefore, indications for this procedure are somewhat subjective. Measurements of the chest deformity are generally performed using the inclinometer (scoliometer), and measurements in excess of $15^{\circ}$ are considered significant enough to warrant the procedure. In young patients with good pulmonary function the procedure will effectively reduce the "hump-back" deformity, thus improving their body image. The thoracoplasty provides a copious amount of bone graft and usually prevents iliac crest bone graft harvest. These positive effects are worthwhile, and thoracoplasty is performed in the majority of our patients with thoracic and thoracolumbar scoliosis cases after a detailed explanation of the benefits and risks of the procedure (Fig. 1).

\section{COMPLICATION AVOIDANCE AND MANAGEMENT OF INSTRUMENTED FUSIONS}

\section{Trunk Decompensation}

The goal of surgery in patients with scoliosis has always been to stop progression of the deformity by bone fusion and to correct the deformity itself. The surgeon endeavors to correct the deformity by fusing as few segments as possible and especially trying to preserve lumbar vertebrae. Therefore, choosing levels for instrumentation and fusion becomes a critical part of the surgical planning. When mistakes are made in choosing the vertebral levels for the placement of instrumentation, the result can be persistent deformity or trunk decompensation when further spinal growth occurs[8,33] (Table 8). Although 
achievement of greater correction may mean fewer segments need to be fused in some cases, it also may impart torsional forces in segments that were not fused, resulting in persistent or new deformity. Trunk decompensation is produced when correction of the upper spine exceeds the capacity of the lower, uninstrumented segment of the spine to attain spontaneous correction. In this situation, the lower spinal segment remains structurally deformed, leaving an oblique take-off from the sacrum. The problem produces cosmetic deformity and theoretically predisposes the patient to arthritis by asymmetrical loading of the vertebral segments.

\section{TABLE 8}

\section{CAUSES OF SPINAL DECOMPENSATION AFTER POSTERIOR INSTRUMENTATION}

instrumentation placed cephalic to stable vertebra

partial instrumentation extending to the lower structural cur ie

progressive scoliosis below instumentation

excessi ve correction or translation of upper cur'ie

fajlure to recognize a 2 nd upper thoracic structural curve

The most predictable trunk balance is achieved by fixing the instrumentation to the stable vertebrae.[26] However, for double major curves (King types 1 and 2), L-4 may be the lower stable vertebra. Therefore, a dilemma exists because the majority of evidence suggests that early lumbar spine arthritis will develop when fusion is extended to L-4 and below. An alternative procedure in cases of King type 2 curves is to perform selective fusion of the thoracic component, stopping at the neutral and stable lower thoracic vertebrae, usually T-11 or T-12. For selective fusion procedures, the lower curve must be flexible and the apex of the upper curve must not be translated past the midline. Distraction and transverse traction should be applied and rotation avoided for selective instrumentation in cases of King type 2 curves because the counterrotation created in the lumbar spine when rotational maneuvers are used may limit the improvement in the lumbar curves. Furthermore, partial instrumentation of the lower curve must be avoided. In cases of flexible King type 3 and 4 curves, extending the fusion no farther than the neutral vertebrae may produce acceptable results if the neutral vertebrae comes into the stable zone on side-bending radiographs and the underlying disc space opens toward the apex. When treating large structural lumbar curves (King type 1 and 2 curves) with instrumentation, the lumbar component must be included to achieve adequate correction (Fig. 1). Unfortunately this means that the fusion usually needs to extend to L-4. The alternative for isolated lumbar and thoracolumbar curves is to use anterior instrumentation that extends to L-3.[6,26]

\section{Pseudarthrosis and Metal Failure}

The use of spinal instrumentation has enhanced our ability to achieve correction spinal in patients with scoliosis; however, halting progression and maintaining correction is ultimately dependent on achieving a bony fusion. Factors that have an impact on the ability to obtain fusion include the source of bone graft, surgical techniques, magnitude of the deformity, and the healing potential of the patient. Autogenous bone graft produces the best fusion and is preferable when available.[6,44] However, in patients with severely osteopenic bone, such as those with cerebral palsy and muscular dystrophy, or in small children, adequate autograft may not be available and allogenic bone will have to be used. Cancellous bone is the preferred graft material for placement within the denuded facets as well as on the decorticated laminae and transverse processes. If structural stability is required such as in cases postvertebrectomy, then cortical graft, either fibula, rib, or tricortical iliac crest, should be used. Fusions occur best when the bone is under compressive forces, such as in the concavity of the scoliosis, and heal poorly when they are 
under excessive tension, such as after posterior bone placement in patients with a large kyphotic deformity.

Attention to surgical detail will also enhance fusion rates and increase the potential for curvature correction. Thorough facetectomies should be performed and graft material placed within the joints prior to placement of the rods. Once rods are in place, access to the facets is limited. Hook claws should be used in areas where bending loads are high, such as at the end of the construct. In most cases of spinal surgery, a race against time exists between the degeneration of the implants and the formation of a solid bony fusion.

One or more of the following symptoms and signs will indicate the presence of a pseudarthrosis: pain, progressive deformity, or metal failure (rod breakage or hook pullout). Imaging studies, such as computerized tomography or bone scans, can be obtained to confirm the diagnosis and location of the pseudoarthrosis. If signs of pseudarthrosis are present, then exploration and grafting of the defect is recommended. The defect will usually be found in the area in which tension exits. Treatment entails removal of all fibrous tissue, copious bone grafting, and placement instrumentation designed to produce compression across the site. Cultures should be obtained as a matter of routine practice because of the high association between infections and pseudarthroses.

\section{POSTOPERATIVE INFECTIONS}

In this modern era of spinal instrumentation postoperative infections are inevitable because of the large amount of metal implanted including rods, cross-links and multiple hooks.[51,52,58,59] The routine use of perioperative antibiotic medications has kept the incidence of infection for idiopathic cases to approximately one per 100 cases, whereas in neuromuscular cases the rate rises to approximately $5 \%$. Factors that predispose to infection include development of a hematoma, preoperative dermatological conditions, and concurrent infections such as urinary tract infection and poor nutrition. Copious irrigation and relaxation of retractors during the surgery is important to prevent infection. We routinely administer antibiotics every 4 hours during lengthy procedures and perform pulse lavage by using $3 \mathrm{~L}$ of antibiotic irrigation prior to closure.

Persistent fever greater than $101.5^{\circ} \mathrm{F}$ after the 5 th day postoperatively should heighten suspicion that an acute wound infection is present. Adequate evaluation includes obtaining a culture sample of all blood, urine, and pulmonary systems, and aspiration of the wound. A purulent aspirate or a persistent large hematoma should be treated aggressively by performing irrigation in the operating room. Parenteral antibiotics should be administered promptly after irrigation until culture samples have been examined. If an established infection is found, loose bone graft should be removed, and most surgeons close the sites over a drain. Other options include performing the closure over a close suction-irrigation system or leaving the wound open for packing and allowing healing to occur by secondary intention. The latter method is generally reserved after failure of the other options. Similarly, the duration of antibiotic therapy and the route of administration will vary. Commonly, parenteral use of antibiotics for at least 3 weeks is followed by oral use for an additional 3 weeks. The sedimentation rate is useful to follow; however, it may not normalize for several weeks after treatment of the acute inflammation. Therefore, undertreatment is unlikely if this parameter is used as a guide.

Delayed infections are now well recognized following spinal surgery, and recent reports have linked these to posterior instrumentation in which the CD system is used.[42,61] Patients present with back pain, signs of inflammation, or drainage months to years after spinal surgery. The most common 
infectious organisms are Staphylococcus epidermidis, Propionibacterium acnes, and other skin flora.[51,59] These low virulent organisms are felt to contaminate the wound at the time of surgery and remain subclinical for an extended period of time. The protocol for treatment of these infections is the same as in acute infections. The first treatment should be aggressive irrigation, debridement, and wound drainage. Healing by secondary intention may be necessary for cases in which the initial attempts fail. Rarely will the hardware have to be removed to control spinal infections. In fact, every attempt to salvage the instrumentation should be made. Pseudarthroses are common following infections and, if symptomatic, they should be treated by autogenous grafting once the infection has been treated. Postoperative antibiotics should be utilized for several weeks postgrafting to reduce the chance of a recurrence.

\section{SUMMARY}

The optimum surgical strategy for managing of idiopathic thoracic and thoracolumbar scoliosis continues to evolve. Whereas excellent results have been obtained in most cases by performing posterior fusion with instrumentation alone, the use of anterior exposures has been gaining popularity in certain cases because biomechanical advantages have permitted improved correction and the potential to save fusion levels. The incidence of hardware failure with anterior instrumentation and arthrodesis has been reduced because newer, stronger instrumentation systems have been developed. The most complicated cases of deformity such as in children and adults with large rigid curves and young children with significant deformity and significant amounts of spinal growth remaining, the preferred treatment is becoming a combined anterior-posterior approach. Although combined approaches performed to treat complex deformity are usually time-consuming and complicated surgical procedures, they usually achieve better correction, fuse fewer spinal levels, have a reduced incidence of pseudarthrosis, and result in better long-term outcomes. The goals of all surgical procedures for spinal deformity are to provide the patient with a well-balanced, functional, and pain-free spinal column. By appropriately selecting one of the approaches discussed, the procedure can be tailored to achieve the best result with the least attendant morbidity.

\section{References}

1. Andrew T, Piggott H: Growth arrest for progressive scoliosis. Combined anterior and posterior fusion of the convexity. J Bone Joint Surg (Br) 67:193-197, 1985

2. Ascani E, Bartolozzi P, Logroscino CA, et al: Natural history of untreated idiopathic scoliosis after skeletal maturity. Spine 11:784-789, 1986

3. Betz RR, Harms J, Clements DH III, et al: Comparison of anterior and posterior instrumentation for correction of adolescent idiopathic scoliosis. Spine 24:225-239

4. Bridwell KH: Adolescent idiopathic scoliosis: surgical treatment, in Weinstein SL (ed): The Pediatric Spine: Principles and Practice. New York: Raven Press, 1994, pp 511-556

5. Bridwell KH: Spinal instrumentation in the management of adolescent scoliosis. Clin Orthop 335:64-72, 1997

6. Bridwell KH: Surgical treatment of adolescent idiopathic scoliosis: the basics and the controversies. Spine 19:1095-1100, 1994 
7. Bridwell KH, Betz R, Capelli AM, et al: Sagittal plane analysis in idiopathic scoliosis patients treated with Cotrel-Dubousset instrumentation. Spine 15:921-926, 1990

8. Bridwell KH, McAllister JW, Betz RR, et al: Coronal decompensation produced by Cotrel-Dubousset "derotation" maneuver for idiopathic right thoracic scoliosis. Spine 16:769-777, 1991

9. Brown JC, Swank S, Specht L: Combined anterior and posterior spinal fusion in cerebral palsy. Spine 7:570-573, 1982

10. Byrd JA III, Scoles PV, Winter RB, et al: Adult idiopathic scoliosis treated by anterior and posterior spinal fusion. J Bone Joint Surg (Am) 69:843-850, 1987

11. Carr WA, Moe JH, Winter RB, et al: Treatment of idiopathic scoliosis in the Milwaukee brace: long-term results. J Bone Joint Surg (Am) 62:599-612, 1980

12. Cochran T, Irstam L, Nachemson A: Long-term anatomic and functional changes in patients with adolescent idiopathic scoliosis treated by Harrington rod fusion. Spine 8:576-584, 1983

13. Connolly PJ, Von Schroeder HP, Johnson GE, et al: Adolescent idiopathic scoliosis. Long-term effect of instrumentation extending to the lumbar spine. J Bone Joint Surg (Am) 77:1210-1216, 1995

14. Dick J, Boachie-Adjei O, Wilson M: One-stage versus two-stage anterior and posterior spinal reconstruction in adults. Comparison of outcomes including nutritional status, complication rates, hospital costs, and other factors. Spine 17 (Suppl 8):S310-S316, 1992

15. Dubousset J, Hering JA, Shufflebarger H: The crankshaft phenomenon. J Pediatr Orthop 9:541-550, 1989

16. Dwyer AF: Experience of anterior correction of scoliosis. Clin Orthop 93:191-214, 1973

17. Floman Y, Micheli LJ, Penny JN, et al: Combined anterior and posterior fusion in seventy-three spinally deformed patients: indications, results and complications. Clin Orthop 164:110-122, 1982

18. Grossfeld S, Winter RB, Lonstein JE, et al: Complications of anterior spinal surgery in children. J Pediatr Orthop 17:89-95, 1997

19. Hall JE, Levine CR, Sudhir KG: Intraoperative awakening to monitor spinal cord function during Harrington instrumentation and spine fusion. Description of procedure and report of three cases. $\mathbf{J}$ Bone Joint Surg (Am) 60:533-536, 1978

20. Halm HF, Liljenqvist U, Niemeyer T, et al: Halm-Zielke instrumentation for primary stable anterior scoliosis surgery: operative technique and 2-year results in 10 consecutive adolescent idiopathic scoliosis patients within a prospective clinical trial. Eur Spine J 7:429-434, 1998

21. Harrington PR: Surgical instrumentation for management of scoliosis. J Bone Joint Surg (Am) 42:1448, 1960 (Abstract)

22. Harrington PR: Technical details in relation to the successful use of instrumentation in scoliosis. Orthop Clin North Am 3:49-67, 1972

23. Hopf CG, Eysel P, Dubousset J: Operative treatment of scoliosis with Cotrel-Dubousset-Hopf instrumentation. New anterior spinal device. Spine 22:618-627, 1997 
24. Kaneda K, Shono Y, Satoh S, et al: Anterior correction of thoracic scoliosis with Kaneda anterior spinal system. A preliminary report. Spine 22:1358-1368, 1997

25. Katz DE, Richards BS, Browne RH, et al: A comparison between the Boston brace and the Charleston bending brace in adolescent idiopathic scoliosis. Spine 22:1302-1312, 1997

26. King HA, Moe JH, Bradford DS, et al: The selection of fusion levels in thoracic idiopathic scoliosis. J Bone Joint Surg (Am) 65:1302-1313, 1983

27. Lenke LG, Bridwell KH, Baldus C, et al: Cotrel-Dubousset instrumentation for adolescent idiopathic scoliosis. J Bone Joint Surg (Am) 74:1056-1067, 1992

28. Lonstein JE, Carlson JM: The prediction of curve progression in untreated idiopathic scoliosis during growth. J Bone Joint Surg (Am) 66:1061-1071, 1984

29. Lonstein JE, Winter RB: The Milwaukee brace for the treatment of adolescent idiopathic scoliosis. A review of one thousand and twenty patients. J Bone Joint Surg (Am) 76:1207-1221, 1994

30. Lowe TG, Peters JD: Anterior spinal fusion with Zielke instrumentation for idiopathic scoliosis: a frontal and a sagittal curve analysis in 36 patients. Spine 18:423-426, 1993

31. Maiocco B, Deeney VF, Coulon R, et al: Adolescent idiopathic scoliosis and the presence of spinal cord abnormalities. Preoperative magnetic resonance imaging analysis. Spine 22:2537-2541, 1997

32. Mandelbaum BR, Tolo VT, McAfee PC, et al: Nutritional deficiencies after staged anterior and posterior spinal reconstructive surgery. Clin Orthop 234:5-11, 1988

33. Mason DE, Carango P: Spinal decompensation in Cotrel-Dubousset instrumentation. Spine 16 (Suppl 8):S394-S403, 1991

34. McCance SE, Denis F, Lonstein JE, et al: Coronal and sagittal balance in surgically treated adolescent idiopathic scoliosis with the King II curve pattern. A review of 67 consecutive cases having selective thoracic arthrodesis. Spine 23:2063-2073, 1998

35. Mehta MH: The rib-vertebra angle in the early diagnosis between resolving and progressive infantile scoliosis. J Bone Joint Surg (Br) 54:230-243, 1972

36. Owen R, Turner A, Banforth JSG, et al: Costectomy as the first stage of surgery for scoliosis. J Bone Joint Surg (Br) 68:91-95, 1986

37. Padberg AM, Wilson-Holden TJ, Lenke LG, et al: Somatosensory- and motor-evoked potential monitoring without a wake-up test during idiopathic scoliosis surgery. An accepted standard of care. Spine 15:1392-1400, 1998

38. Powell ET IV, Krengel WF III, King HA, et al: Comparison of same-day sequential anterior and posterior spinal fusion with delayed two-stage anterior and posterior spinal fusion. Spine 19:1256-1259, 1994

39. Richards BS: Delayed infections following posterior spinal instrumentation for the treatment of idiopathic scoliosis. J Bone Joint Surg (Br) 77:524-529, 1995

40. Richards BS, Herring JA, Johnston CE, et al: Treatment of adolescent idiopathic scoliosis using 
Texas Scottish Rite Hospital instrumentation. Spine 19:1598-1605, 1994

41. Risser JC, Norquist DM, Cockrell BR Jr, et al: The effect of posterior spine fusion on the growing spine. Clin Orthop 46:127-139, 1966

42. Roberto RF, Lonstein JE, Winter RB, et al: Curve progression in Risser stage 0 or 1 patients after posterior spinal surgery for idiopathic scoliosis. J Pediatr Orthop 17:718-725, 1997

43. Schwend RM, Hennrikus W, Hall JE, et al: Childhood scoliosis: clinical indications for magnetic resonance imaging. J Bone Joint Surg (Am) 77:46-53, 1995

44. Shufflebarger HL: Surgical treatment of scoliosis, in Welch WC, Jacobs GB, Jackson RP (eds): Operative Spine Surgery. Stamford, Conn: Appleton \& Lange, 1999, pp 202-227

45. Shufflebarger HL, Clark CE: Prevention of the crankshaft phenomenon. Spine 16 (Suppl 8):S409-S411, 1991

46. Shufflebarger HL, Grimm JO, Bui V, et al: Anterior and posterior spinal fusion. Staged versus same-day surgery. Spine 16:930-933, 1991

47. Shufflebarger HL, Smiley K, Roth HJ: Internal thoracoplasty. A new procedure. Spine 19:840-842, 1994

48. Soucacos PN, Zacharis K, Gelalis J, et al: Assessment of curve progression in idiopathic scoliosis. Eur Spine J 7:270-277, 1998

49. Stasikelis PJ, Pugh LI, Allen BL Jr: Surgical corrections in scoliosis: a meta-analysis. J Pediatr Orthop (B) 2:111-116, 1998

50. Steel HH: Rib resection and spine fusion in correction of convex deformity in scoliosis. J Bone Joint Surg 65:920-925, 1983

51. Theiss SM, Lonstein JE, Winter RB: Wound infections in reconstructive spine surgery. Orthop Clin North Am 27:105-110, 1996

52. Tredwell SJ: Complications of spinal surgery, in Weinstein SL (ed): The Pediatric Spine:

Principles and Practice. New York: Raven Press, 1994, pp 1761-1786

53. Turi M, Johnston CE II, Richards BS: Anterior correction of idiopathic scoliosis using TSRH instrumentation. Spine 18:417-422, 1993

54. Weinstein SL: Adolescent idiopathic scoliosis: prevalence and natural history, in Weinstein SL (ed): The Pediatric Spine: Principle and Practice. New York: Raven Press, 1994, pp 463-478

55. Weinstein SL: Idiopathic scoliosis. Natural history. Spine 11:780-783, 1986

56. Weinstein SL, Ponseti IV: Curve progression in idiopathic scoliosis. J Bone Joint Surg (Am) 65:447-456, 1983

57. Weinstein SL, Zavala DC, Ponseti IV: Idiopathic scoliosis: long-term follow-up and prognosis in untreated patients. J Bone Joint Surg (Am) 63:702-712, 1981 
58. Weis JC, Betz RR, Clements DH III, et al: Prevalence of perioperative complications after anterior spinal fusion for patients with idiopathic scoliosis. J Spinal Disord 10:371-375, 1997

59. Wimmer C, Gluch H: Aseptic loosening after CD instrumentation in the treatment of scoliosis: a report about eight cases. J Spinal Disord 11:440-443, 1998

60. Winter RB, Lonstein JE, Drogt J, et al: The effectiveness of bracing in the nonoperative treatment of idiopathic scoliosis. Spine 11:790-791, 1986

61. Winter RB, Lonstein JE, Heithoff KB, et al: Magnetic resonance imaging evaluation of the adolescent patient with idiopathic scoliosis before spinal instrumentation and fusion. A prospective, double-blinded study of 140 patients. Spine 22:855-858, 1997

Manuscript received March 22, 1999.

Accepted in final form April 30, 1999.

Address reprint requests to: Michael J. Rauzzino, M.D., Departments of Neurosurgery and Surgery, Henry Ford Hospitals, 2799 West Grand Boulevard, Detroit, Michigan 48202. 